\title{
CLAVES GEOGRÁFICAS PARA LA INTERPRETACIÓN DEL PATRIMONIO HIDRÁULICO MEDITERRÁNEO. A PROPÓSITO DE LOS REGADÍOS HISTÓRICOS VALENCIANOS
}

\author{
Jorge Hermosilla Pla \\ Emilio Iranzo García \\ Departamento de Geografía. Universitat de València \\ ESTEPA. Estudios de Territorio, del Paisaje y del Patrimonio \\ Jorge.Hermosilla@uv.es, Emilio.Iranzo-Garcia@uv.es
}

«La totalidad de los paisajes del agua responden a una coherencia en la adaptación al medio físico»

Rafael Mata (2010)

\section{RESUMEN}

Los regadíos tradicionales valencianos son unidades espaciales de contrastado valor patrimonial y paisajístico. Desde la disciplina geográfica y, concretamente desde la perspectiva de la geografía cultural, son identificadas las claves del análisis geográfico del patrimonio relacionado con los regadíos históricos. En ese sentido, se reflexiona sobre los aspectos y las claves que definen ese patrimonio singular que forma parte de la cultura territorial de los valencianos.

Palabras clave: Geografía cultural. Patrimonio hidráulico. Arquitectura del agua. Regadíos históricos valencianos. Paisajes del agua. Procesos de transformación del regadío.

\section{ABSTRACT}

The valencian traditional irrigation systems are spatial units of contrasted heritage and landscape value. From the geographical discipline and, specifically from the perspective

Fecha de recepción: septiembre 2012.

Fecha de aceptación: julio 2013. 
of cultural geography, the keys of the geographical analysis of the heritage related with the historical irrigation are identified. In that regard, reflections are made on the aspects that define this unique heritage which is part of the culture of the valencians.

Key words: Cultural geography. Hydraulic heritage. Architecture of the water. Valencian historical irrigation. Water landscapes. Processes of transformation of irrigation.

\section{LA GEOGRAFÍA, UN ENFOQUE ESPACIAL DEL PAISAJE Y DEL PATRIMONIO}

Es la Geografía una disciplina plural definida entre otros rasgos por su transversalidad. Siguiendo a Hagget (1989), se trata de una disciplina que al menos aborda media docena de temas fundamentales, como son la diferenciación espacial, el paisaje cultural y la apariencia directamente perceptible del espacio, las relaciones entre el hombre y el medio, la distribución de la actividad humana en el espacio, y finalmente, la representación del espacio, mediante la cartografía. Un planteamiento formal más sintético es aquél que aboga por una ciencia que, como afirma Miralbés e Higueras (1993), estudia las estructuras espaciales o la organización del espacio, por lo que debe explicar los elementos y los factores que fundamentan el orden interno de dicho espacio. En conjunto, se trata de planteamientos complementarios en los que coinciden la cualidad diferenciadora de la Geografía, disciplina responsable del estudio de la configuración del espacio, el cual se caracteriza por su falta de homogeneidad y por su diversidad funcional. A esa heterogeneidad, que se traduce y visualiza en una variedad geográfica, le corresponde una manifiesta variedad cultural, pues cada territorio es interpretado de una manera concreta por la comunidad que en él habita. Cada territorio refleja las diversas formas de relación entre las sociedades y el medio natural. El resultado es una amalgama de manifestaciones objetuales e inmateriales que dan lugar a diferentes paisajes. En ese sentido, los paisajes son el resultado de la integración del patrimonio natural y el cultural.

\section{El espacio geográfico, el lugar y el patrimonio}

El espacio geográfico, entendido como territorio, comprende una serie de componentes que lo organizan y modelan. Para Claval (1999), un espacio está estructurado en función de las condiciones naturales, la impronta que supone las condiciones del medio físico; los procesos históricos, condicionados por las organización de la sociedad durante las diferentes etapas; y las acciones de sus actuales moradores, dirigidas a hacerlo habitable. El condicionamiento físico, el pasado y el presente son las bases de todo territorio. La humanidad en su relación con el espacio natural construye para habitar el territorio; y el hecho de habitar da lugar a la creación del lugar. Un lugar adquiere, en consecuencia, una función de sociabilidad que lo diferencia del resto de espacios geográficos.

Los lugares, según Aguiló (1999), poseen un alto contenido de información y generan sentimientos entre la sociedad que los habitan. La construcción se convierte en seña de identidad y por tanto en patrimonio. A diferencia de los espacios geográficos, los lugares se caracterizan por una estructura común, basada en tres elementos integrantes. De nuevo el medio físico, que es habitualmente la parte más perceptible del lugar; la actividad antrópica, que guarda relación 
con la función y el uso que se hace de él; y los significados, es decir, los resultados de las experiencias e intenciones humanas que consolidan la identidad de los sitios.

El funcionamiento de esos tres componentes, que además se relacionan entre sí, configuran la base de la dinámica de un lugar. Un lugar es un espacio dinámico, en el que se van sucediendo cambios en el medio físico, en el uso del territorio y en los significados que asientan la identidad del lugar. La acumulación de significados genera un proceso de fortalecimiento de la identidad del sitio y lo hacen perdurar. Se transforma, en definitiva, en un espacio cultural. Cuando en ese espacio cultural se valorizan los recursos propios, los conocimientos y técnicas propias de la sociedad que habita el lugar, y la colectividad los asume como señas de identidad, se convierte en espacio patrimonial.

\section{La Geografía, la Geografía Cultural y el análisis geográfico del patrimonio}

El estudio del patrimonio desde la Geografía está motivado por la intensa vinculación existente entre las sociedades y su territorio, pues un espacio poblado genera unas manifestaciones y unos símbolos que tienen una plasmación directa sobre el territorio. La Geografía se convierte en una disciplina clave en la interpretación del espacio mediante los bienes patrimoniales, pues en ellos la población se reconoce, busca explicación del territorio en el que vive y sobre el cual construirán lugares las generaciones futuras. El geógrafo cultural efectúa una interpretación de los bienes culturales, las motivaciones y contextos sociales que los originaron, con el propósito de explicar el paisaje resultante. Es por ello por lo que estudia tanto lo material como lo inmaterial; e investiga cómo las manifestaciones de la actividad humana, las emociones y las ideologías interaccionan y, con el medio físico como soporte, conforman lugares específicos en el tiempo (Anderson, 2009)

La relación que establece una comunidad con el entorno en el que vive explica la constitución de una cultura propia. Como señala Rioja (1999), es el motivo de la creación de «áreas culturales», superficies territoriales que incorporan entes de índole diversa y que explican la vida de las comunidades precedentes y actuales. La Geografía se ocupa del análisis de esas áreas culturales, de las unidades de paisaje, producto de las relaciones que los individuos y grupos establecen con la naturaleza, y que integran un patrimonio cultural y natural con el que la comunidad se siente identificada. Por tanto, el geógrafo tiene varios cometidos como son el estudio de los modos de organización del espacio terrestre, y el análisis de los paisajes, su examen, descripción, definición de las formas y su disposición en el espacio, así como el análisis de las relaciones existentes entre todos los elementos que aparecen en el paisaje, entre los cuales destaca el patrimonio. El paisaje es una expresión cultural, fruto del tiempo y de un lugar y, por tanto, propósito geográfico.

La Geografía Cultural constituye una subdisciplina poco conocida, que ha evolucionado su epistemología: desde el análisis de las estructuras antrópicas tangibles para la comprensión de los modos de vida y paisajes, hasta los nuevos enfoques más interesados en los aspectos figurativos y simbólicos del paisaje (Mitchell, 1996). Así pues la Geografía Cultural nos ayuda a profundizar en dos campos como el patrimonial y el paisajístico. Permite relacionar los contextos culturales en el territorio; intenta comprender y explicar el papel del territorio en la construcción de marcos culturales (Capellà y Lois, 2002). Cuando un geógrafo analiza el espacio desde el enfoque cultural adquiere mucha información 
sobre su propia cultura, pues se basa en el estudio de las expresiones culturales, es decir, del patrimonio y del paisaje que este último configura (Iranzo, 2009; Hermosilla, 2011). El paisaje es considerado como una modalidad más de patrimonio, en tanto en cuanto se considera huella de la sociedad sobre la naturaleza y paisajes preexistentes.

Son numerosos y variados los vestigios y las señales que las sociedades han dejado en el espacio geográfico, lo que ha permitido una configuración variada de paisajes en función de la componente dominante. Entre las diversas modalidades de paisajes «temáticos» resultantes sobresalen en los territorios mediterráneos los relacionados con el agua. Los paisajes del agua (Mata y Fernández, 2010) son aquellos sistemas paisajísticos en los que el agua desempeña un papel esencial en su origen y configuración, en su dinámica, y en la percepción social y cultural del territorio. En ese sentido, adquieren la misma importancia y valor en su definición las relaciones históricas y presentes entre el recurso natural, el agua, y la acción antrópica, las sociedades locales principalmente; del mismo modo es importante la percepción multidimensional de estas relaciones, que recoge tanto la contemplación, la información y la comprensión, como la concienciación e incluso el compromiso.

Los regadíos tradicionales mediterráneos, reconocidos mediante las unidades paisajísticas de las huertas, las vegas y las riberas, son unidades espaciales de innegable valor patrimonial y paisajístico. Dicho valor contrasta en ocasiones con su actual función productiva agraria, frecuentemente cuestionada y devaluada. E incluso con la escasa atención y frecuencia que son recogidos en los propios estudios de los regadíos históricos desde un enfoque cultural. El estudio de la agricultura requiere un planteamiento multidisciplinar, dado el carácter plurifuncional de esta actividad ancestral (Silva, 2008): la producción de alimentos, la configuración de méritos culturales, paisajísticos o patrimoniales relacionados con el agro, y el cumplimiento de funciones relacionadas con la preservación ambiental, el reequilibrio territorial o la generación de espacios lúdicos. Tradicionalmente la agricultura ha sido objeto de estudio sobre todo como actividad productiva, generadora de alimentos y materias primas industriales, mientras que los planteamientos en los cuales la consideran por significados y cometidos no se han desarrollado. Durante décadas los estudios de Geografía Agraria clásica destacaron sobre los de la Geografía Cultural. No obstante en los últimos años asistimos a una paulatina superación de ese enfoque tradicional, de tal manera que se asiste a una apertura de significados y planteamientos de los objetos de estudio, mediante la consideración patrimonial de la agricultura. Las actividades y las estructuras agrícolas se perciben como expresiones de nuestra memoria común, que nos ayudan a comprender la relación entre el pasado y el presente, entre la naturaleza y las diferentes culturas que han habitado el territorio. Además, todo este patrimonio cultural basado en el conocimiento tradicional es considerado como una fuente de valor añadido para el medio rural. O dicho de otro modo un recurso para el desarrollo rural (Daugstad, Rønningen y Skar, 2006)

Así, se tiende a una mayor apreciación del significado patrimonial de los espacios agrícolas. Se ha pasado del estudio del hito aislado a la valoración del conjunto, del sistema espacial, de la agrupación. Sin perder de vista los valores culturales de una hacienda señorial, un palacete urbano o una fábrica harinera, se está experimentando un recorrido conceptual que prima el estudio patrimonial de un núcleo urbano rural, del espacio de cultivo en abancalamiento, de la red de molinos hidráulicos o del paisaje resultante. Se trata 
de un recorrido conceptual que ha permitido el reconocimiento patrimonial del legado de la agricultura (Silva, 2008).

\section{LOS REGADÍOS HISTÓRICOS VALENCIANOS. UNIDADES PAISAJISTICAS MEDITERRÁ- NEAS DE VALOR PATRIMONIAL}

En las regiones de clima mediterráneo, los paisajes de regadío constituyen las «expresiones más acabadas de los paisajes culturales del agua», y se configuran en señas de identidad de unidades territoriales de diferente escala. Son a la vez culturales y patrimoniales, porque expresan una larga historia de adaptación al medio natural, y porque generan relaciones de afinidad e identidad (Mata y Fernández, 2010). Esa adaptación ha dado lugar a dos modelos resultantes de contrapuestos regadíos tradicionales, el fluvial-litoral-periurbano y el ruralserrano, perteneciente a los agrosistemas de montaña; paisajes asociados respectivamente a las aguas superficiales circulantes, a los ríos, ramblas y llanuras de inundación, a los acuíferos aluviales, así como a fuentes y manantiales tradicionalmente aprovechados para abastecimiento humano y para la construcción de históricos regadíos.

La existencia y posible uso de recursos hídricos para el riego se ha configurado en un factor de localización del poblamiento en tierras mediterráneas, de tal manera que la existencia de regadíos está asociada a la presencia de los variados y múltiples núcleos de población, desde las ciudades a las entidades menores. Se trata, en ese sentido, de lugares próximos y cercanos para los ciudadanos, pues ha sido tradicional la existencia de espacios irrigados durante décadas, cuando no siglos, en los entornos de dichas entidades de población. Esta circunstancia dio lugar a un paisaje de regadío, histórico, integrado por multitud de áreas irrigadas, que adoptan las formas de huertas, vegas, riberas, oasis, etc., y junto a ellos, ciudades, pueblos o aldeas repartidas por la geografía valenciana.

Por lo tanto, el regadío histórico mediterráneo es consecuencia de una adaptación al medio natural y, a su vez, a una dinámica histórica particular que ha dado lugar a un predominio del minifundismo, a una estructura parcelaria atomizada. La función tradicional de estos espacios agrícolas, la producción de alimentos para las demandas urbanas, se ha visto modificada, cuando no trastocada, por las nuevas lógicas de la agricultura comercial. Este proceso, no ajeno a otros relacionados con la urbanización de la segunda mitad del siglo XX, generó un retroceso de la producción agrícola, un estado regresivo de los sistemas y elementos que configuran la arquitectura de los regadíos y la transformación, cuando no mutación, de los paisajes del regadío mediterráneo.

El valor patrimonial de los regadíos históricos es consecuencia de una combinación de factores que dan lugar a paisajes valiosos y valorados. Entre esos factores cabe señalar las estructuras espaciales dibujadas por las infraestructuras hidráulicas (sintetizadas en la red de acequias) y las de comunicación (red de caminos); la estructura de la propiedad, minifundista, que da lugar a una morfología de campos cerrados y puzzles parcelarios; la apariencia adoptada por el poblamiento agrario ligado al regadío, habitualmente en construcciones en diseminado o en poblaciones de pequeño tamaño; y la variedad de los productos cultivados, traducida en mosaicos de cultivos. Son paisajes valorados, espacios próximos y familiares, caracterizados por un elevado valor simbólico y un arraigado sentimiento identitario. 


\section{LAS CLAVES PARA LA INTERPRETACIÓN DE LOS REGADÍOS HISTÓRICOS VALENCIANOS}

\section{A) Un paisaje cultural mediterráneo, coherente con el medio físico}

El paisaje se considera un todo territorial morfológico, funcional y percibido. Los paisajes del agua culturales son aquellos territorios cuyo carácter (término polisémico) responde en un alto grado a las relaciones, históricas y actuales, entre un factor natural de primer orden como el agua y la acción humana, según Mata. Todo ello, tal y como es percibido por la gente, percepción que supone no sólo visión o contemplación, sino también información, comunicación y representaciones sociales.

Los regadíos históricos mediterráneos constituyen como se ha apuntado ya las expresiones más acabadas de los paisajes culturales del agua de escala local, y constituyen al mismo tiempo las señas de identidad mayores de numerosas comarcas y regiones. Son a la vez culturales (expresan una larga historia) y patrimoniales (representan relaciones de afinidad e identidad). Además de coherentes con el medio físico que les acoge: se manifiesta una dependencia, una ligazón, con la base geográfica física. Los regadíos históricos son una consecuencia de las relaciones de adaptación; son espacios legibles y coherentes con su medio. No cabe duda que la topografía, o la gravedad como indica Barceló (1989), condiciona el diseño, las dimensiones y por tanto las características distintivas de los sistemas de riego. Los labradores, niveladores, maestros de obra e ingenieros fueron conscientes entonces del condicionamiento físico, de la necesidad de adaptación al medio y de los resultados de contrastes esperados, los riegos estrechos de los valles y laderas abancaladas en yuxtaposición con la expansión de redes de regadío en las llanuras litorales.

\section{B) Unas condiciones espaciales particulares, basadas en la universalidad, la invisibilidad, la versatilidad y la complejidad del uso del agua}

Una de las cualidades que permiten la interpretación de los regadíos históricos es la «universalidad» del recurso hídrico, dado que está presente, en mayor o menor medida, en muchos paisajes: lo está como elemento morfológico percibido; en ocasiones, como componente funcional de primer orden del sistema paisajístico; como imagen y representación simbólica en diversas manifestaciones artísticas; y como recurso que por su escasez o ausencia, condiciona la configuración y fisonomía del paisaje. En las tierras valencianas se encuentran testimonios de su uso tradicional, tanto para regadío (en sus diversas escalas espaciales) como para abastecimiento humano.

Una buena parte de los regadíos tradicionales se caracterizan por su «invisibilidad», pues la superficie por las que se extienden en ocasiones es reducida, no es perceptible. Sin embargo, a escala local es cuando adquieren su significado real. En la totalidad de los municipios valencianos se puede constatar la presencia de espacios irrigados, en unos casos en extensas huertas, en otros en reducidos y minúsculos huertos.

En términos generales sobresale la «versatilidad» de los huertos tradicionales, que fueron acogiendo cultivos en función de los cambios acaecidos durante siglos, muestra de su adaptación. Así, el regadío histórico valenciano fue amparando cáñamo, arroz, cereales, hortalizas, árboles frutales o naranjos. La evolución experimentada por los cultivos, en función de las 
condiciones de los mercados, locales o regionales, ha implicado un proceso de arborización de buena parte de estos espacios.

La totalidad de los riegos requieren de un dominio de técnicas y un conocimiento de tecnologías que permitan el uso de los recursos hídricos. Tradicionalmente la gestión del agua se ha caracterizado por su «complejidad técnica». Sin embargo, el principio hidráulico por el que se regía y se rige el sistema de riego era y es simple, basado en las fases de captación, acumulación (no siempre) y distribución del agua, determinado por el principio geográfico de la gravedad. El agua discurre de las partes altas a las bajas.

\section{C) La arquitectura de los regadíos históricos. El armazón de unos paisajes singulares}

La arquitectura que sustenta los regadíos históricos se fundamenta habitualmente en un sistema configurado por la red de acequias y los artilugios dispuestos a lo largo de su trazado. Artilugios ideados para realizar las funciones necesarias para conducir el agua a su destino. En ese sentido, se desarrolla una tipología que responde a las funciones de captación, de transporte, de acumulación, de distribución y de uso. Entre los elementos de captación sobresalen por su universalidad y volumen las presas y los azudes/assuts, distribuidos en los cursos de agua del territorio valenciano. Destacan los levantados sobre los grandes ríos, especialmente el Turia y el Júcar. Las recurrentes y devastadoras crecidas han dado lugar a continuas reconstrucciones de esos azudes. También se construyeron junto a determinados cursos fluviales artilugios como las norias/rodes que permitieron la elevación del agua a cotas superiores. En las ramblas y barrancos, sobre todo de comarcas meridionales, son frecuentes las boqueras empleadas para derivar las aguas turbias (Morales, 1989). Allí donde el nivel freático se hallaba próximo a la superficie fue muy habitual la construcción de aceñas/ senies, como en el Maestrat, el litoral valenciano y norte del litoral alicantino; con cierta frecuencia se usaban para auxiliar el riego fluvial con aguas subterráneas. Posteriormente, con la introducción de la maquinaria de vapor y del motor de explosión, fueron reemplazadas por pozos. En los espacios de marjal se construyeron tahones, bombillos y carabassins. Finalmente destacan las galerías drenantes, también conocidas por minas de agua, cavas o alcavones, de longitudes desiguales que captan el agua en relieves calcáreos.

Los canales son los elementos clásicos de distribución habitual del agua de riego. Contrasta la homogeneidad morfológica de sus diseños, con cajeros de tierra o de obra, con la gran variabilidad terminológica utilizada para establecer el orden de prioridad de las canalizaciones, y no al tamaño real de las mismas (habitualmente definido por la sección del cajero de cada conducción). Cuando se destinan al riego, estas canalizaciones son denominadas genéricamente acequias, que adquieren una terminología específica como acequia madre, filloles, arrobas, braçals, ramals y regadores; cuando su función es el drenaje normalmente a cielo abierto, adquieren denominaciones como escorredors, sequiols, assarbs, azarbes y azarbetas. La necesidad de salvar los desniveles generados por una topografía irregular, ha dado lugar a soluciones específicas, materializadas en galerías de conducción o alcavones, los acueductos y los sifones. Se aprecia una notable diversidad de tipologías de estos elementos motivada por las desiguales dimensiones de los desniveles salvados, por las variables constructivas históricas, por los materiales de construcción disponibles en cada municipio o comarca, y por la capacidad tecnológica del colectivo social impulsor de la obra. Por ejem- 
plo, la construcción de un sifón requiere un mayor dominio y conocimiento de técnicas y cálculos ingenieriles que un acueducto.

Entre los elementos de conducción del agua señalados, las acequias y los que permiten salvar las irregularidades topográficas, se hallan aquellos que permiten la distribución de los recursos hídricos. Nos referimos a los partidores, que se instalan en las propias acequias. La instalación de un tipo determinado de partidor está ligada a los procedimientos operativos de reparto del recurso: si existía la necesidad de repartir el agua en partes alícuotas se levantaban las lenguas/les llengües; los tajamares múltiples eran utilizados cuando había que servir agua en función de la demanda del momento; para las tandas y turnos se acondicionaban derivaciones con compuertas; y para la protección para evitar robos se escondía el partidor en una construcción cerrada, como las fesas de la Ribera, los sistars del Camp de Morvedre o los canos de la Safor. Las almenaras se construyeron con la finalidad de garantizar el retorno del agua excedentaria a ríos y barrancos.

El almacenamiento del agua de riego se efectúa a veces en el mismo canal, con paradas que permiten la acumulación de agua, pero también y es más común mediante balsas y safareigs/albercas, que son habituales en la pequeña hidráulica de la montaña mediterránea.

Ligados a los sistemas de riego por su funcionamiento y evolución, pero sin formar parte de ellos, hallamos el magnífico conjunto de embalses valencianos antiguos, estudiado por López Gómez (1987), integrado por los de Elx, Tibi o Relleu. De la misma manera es interesante la imbricación del patrimonio del regadío con otros elementos del patrimonio hidráulico, como los lavaderos, abrevadores, fuentes, molinos, batanes, fábricas de luz, medidores y galipuentes, que en el pasado formaron parte de un mismo hidrosistema, mediante una gestión conjunta generalmente a cargo de las comunidades rurales y los consejos urbanos.

\section{D) El patrimonio inmaterial relacionado con el regadío histórico}

Los espacios de irrigación están relacionados con una enraizada gestión del agua, que recoge pautas de uso, conocimientos, técnicas e instituciones que se han prolongado a lo largo de la historia. Al lado de las infraestructuras del regadío histórico se desarrolla un rico legado invisible, que es una parte fundamental del hecho patrimonial. El uso social del agua ha configurado un entramado normativo y jurídico, basado en ordenanzas y reglamentos, que además de contribuir al escrupuloso funcionamiento de los sistemas de riego, constituye un relevante patrimonio inmaterial. El regadío generaba además un espacio de relación que favorecía el encuentro de vecinos, tratos o celebraciones religiosas, base de una sólida cultura del agua. Entre las obras de infraestructura y esa cultura del agua hay una ligazón y una estrecha dependencia, una interacción que se retroalimentaba positivamente. Hoy, al mismo tiempo que se demolen obras hidráulicas y se abandonan los campos, se esfuma ese patrimonio inmaterial, de la misma manera que a la inversa, cuando la cultura y la sociedad agraria entran en crisis, el patrimonio acaba por abandonarse y arruinarse. El ejemplo más relevante es el del Tribunal de las Aguas de Valencia, que se enfrenta a la pérdida acelerada de superficie regable y prácticamente es sostenido por su valor simbólico (Sanchis, 1999; Hermosilla, 2007). Desde 2009 es reconocido Patrimonio Cultural Inmaterial de la Humanidad, junto con el Consejo de Hombres Buenos de la Huerta de Murcia. 


\section{E) La componente medioambiental de los regadíos históricos}

Los regadíos históricos son el resultado de una transformación del paisaje natural con criterios de sostenibilidad. Los sistemas de regadío han desempeñado y desempeñan un importante papel ecológico y ambiental, de tal manera que se han mantenido durante siglos hasta la actualidad (Gil Meseguer,2011). Han dado lugar a paisajes que se caracterizan por su coherencia con el potencial agroecológico del medio natural sobre el que se asientan; y representan una gran proximidad espacial y ecológica respecto a los ecosistemas naturales. Según Martinez y Esteve (2001) los ciclos hídricos no son modificados en exceso en el conjunto del sistema río-vega-acuífero aluvial; el sistema presenta una elevada recirculación interna de agua y de nutrientes, y una exportación neta ligada a un comportamiento vectorial desde la cuenca hacia la costa, similar a la que pueden presentar los sistemas fluviales naturales.

\section{F) El factor cronológico de los regadíos históricos valencianos}

Los riegos tradicionales son espacios con una dilatada historia, incluso antes del período romano ya se hallan vestigios, si bien se establecieron las bases de su desarrollo posterior durante los ochos siglos de ocupación musulmana. En términos generales se refieren a espacios irrigados no extensos que fueron construidos con anterioridad a la gran expansión de los regadíos de iniciativa pública, a principios del siglo XX, mediante el impulso del Plan General de Obras Hidráulicas de 1902 o la Ley de Obras de Puesta en Riego de 1932. Se puede considerar como regadío tradicional aquellos espacios irrigados con más de 100 de años de antigüedad (Marco y Sanchis, 2003). La superficie regada considerada como histórica en el territorio valenciano adquiere un significado especial, pues en 1915 se estima que se regaban unas 186.400 hectáreas, que representaban el 13,5\% del regadío español (Hermosilla, 2010). La primera provincia era Valencia, con 107.500 hectáreas irrigadas, seguidas de Alicante (51.300) y Castellón (27.500). Se trata de espacios que han experimentado en las últimas décadas profundas transformaciones, claves en su evolución reciente y futura. Desde los años cincuenta del pasado siglo XX, coincidiendo con el período del desarrollismo español, los regadíos históricos experimentaron una depreciación y en muchos casos una ruptura con respecto a siglos pasados. Los cambios de usos del suelo, los abandonos de las tierras de cultivo, las fragmentaciones parcelarias, las nuevas prácticas agrícolas, etc. fueron las consecuencias de unos procesos de urbanización e industrialización irrespetuosos con el regadío tradicional; de una política agraria estatal centrada en iniciativas de nuevos regadíos, nuevas colonizaciones y de impulso a la concentración parcelaria, lo que repercutió negativamente en las estructuras tradicionales del agro (caminos, canalizaciones, poblamiento, parcelario); y, finalmente, de los cambios experimentados en la agricultura tras la adopción de las mejoras de la revolución verde que sin cuestionar la estructura de la propiedad introdujo mejoras sustanciales en los procesos de producción del agro (Morales y Olcina, 1992). Ese deterioro ha sido y es generalizado, pues se aprecia tanto en las huertas en torno a las grandes ciudades (L'Horta de València), como en los regadíos históricos de los pueblos montanos (interior valenciano) o en áreas subáridas (problemática de los oasis). Desde los años noventa se ha acentuado la situación de crisis en numerosos espacios del regadío tradicional, pues han persistido los procesos de 
desmejora y devaluación de áreas y de sus modos de producción seculares; no obstante han ido apareciendo, y en algunos casos consolidando, diversos movimientos reivindicativos de su valor cultural, de amplia base social, y cuyos objetivos entroncan con la recuperación, la conservación y la restitución de sus funciones. Sirva de ejemplos significativos el colectivo Salvem l'Horta, la Fundació Assut o la Plataforma de Acció Ecologista Agró, que han centrado sus esfuerzos en la protección de los regadíos históricos y los paisajes del agua en la Huerta de València y el entorno de la Albufera.

\section{G) Una nueva dimensión conceptual y normativa de los regadíos históricos valencianos}

El escenario actual de los regadíos históricos, sus problemáticas y sus posibles soluciones alternativas, aparece relacionado cada vez en más ocasiones con movimientos sociales críticos con el desorden territorial, la falta de ordenación territorial, el deterioro paisajístico y ambiental, motivados por el proceso depredador del urbanismo desmesurado de las últimas décadas y los cambios de usos de suelo. En numerosas ocasiones estos movimientos se transforman en plataformas sociales que aúnan colectivos reivindicativos que reclaman la preservación del regadío tradicional, de los paisajes históricos (y actuales) relacionados con el agua, y de las ventajas de promover unas agriculturas periurbanas vinculadas a la producción agrícola de calidad.

Durante los últimos años han emergido nuevas percepciones de la sociedad respecto al significado de esos espacios hidráulicos, o se han recuperado de etapas anteriores. De alguna manera se ha configurado un nuevo escenario, sustentado en una arraigada dimensión tanto conceptual como normativa, que ha dado lugar a la revalorización del patrimonio hidráulico, la conectividad ecológica o la multifuncionalidad de las áreas agrarias. Los regadíos históricos son, además de espacios productivos, lugares con un significado social y cultural, que adquieren valores medioambientales, y que se conciben como espacios de ocio y esparcimiento, especialmente en torno a los núcleos de población. Actúan como espacios de articulación y relación entre las ciudades y sus entornos, áreas de cultivo o escenarios naturales. El marco normativo desarrollado en las diferentes escalas durante estos últimos años ha contribuido a esa revalorización: desde el Consejo de Europa (2000) mediante el impulso del Convenio Europeo del Paisaje, o la inclusión de programas agroambientales para áreas como las huertas mediterráneas en la política agraria de la Unión Europea, a la declaración de Bienes de Interés Cultural (BIC) u otras figuras de protección en patrimonio destinadas a elementos hidráulicos (azudes de la Huerta de Valencia o una sección de la acequia de Mislata en término de Quart de Poblet, en 1’Horta Oest), o figuras de protección en planeamiento municipal (Lugares de Interés Municipal, Parajes Municipales) o subregional, donde los regadíos históricos pueden acogerse a usos de suelo varios, no urbanizables.

\section{H) Las configuraciones espaciales adquiridas por los regadíos históricos mediterráneos}

La arquitectura del agua que ha permitido la existencia del regadío tradicional se ha ido adaptando al medio físico siguiendo los criterios de coherencia y sentido común. En ese sentido, la acción del hombre ha dado lugar a configuraciones espaciales diversas que tienen como rasgo común en su origen la adaptación al medio. Diversos autores como Antonio 
López Gómez (1974, 1975, 1989), Juan Marco, Joan Mateu y Joan Romero (1994), Antonio Gil y Alfredo Morales (1992) o Juan Piqueras (1994) y Jorge Hermosilla (1999-2012), han señalado los diversos aspectos formales, paisajísticos, que adquieren los espacios irrigados tradicionales valencianos, que como ha recogido Rafael Mata (2010), están ligados a la geomorfología del territorio valenciano, especialmente la fluvial, la litoral y la de laderas. Se trata de una tipología similar a la de otros regadíos de la cuenca mediterránea, agrupada en los siguientes formatos:

- Los regadíos de valles y vegas interiores, que conforman manchas irregulares y relativamente extensas, como acontece en los ríos Cànyoles y Albaida en la Vega de Xàtiva, o el río Turia, en los regadíos de los pueblos castillo del Camp de Túria.

- Los riegos de las riberas de los ríos, de fisonomía lineal que contrasta con los paisajes monocromos de los espacios circundantes. El Alto Mijares, el Alto Palancia, el Turia alto y medio, el Vinalopó, el Albaida o el Magro constituyen ríos o tramos de ellos en los que son frecuentes en sus márgenes esta configuración espacial en forma de guirnalda.

- Los riegos de vegas litorales y deltas, desplegados en los cursos bajos de los ríos mediterráneos y en las proximidades de las principales ciudades. Se trata sin duda de los espacios de regadío históricos más conocidos y reconocidos. Desde la Plana Baixa (Baix Millars) a la Safor (Baix Serpis), se configura un gran espacio hidráulico, que engloba la milenaria Huerta de València. O espacios como el Bajo Segura o el Pla de Vinaròs, en sectores meridionales o septentrionales de la Comunitat, respectivamente.

- Los regadíos serranos, frecuentemente dispuestos en sistemas de abancalamiento de laderas muy característicos del interior. Estos huertos escalonados se reparten por la geografía valenciana, allá donde la topografía irregular y accidentada es habitual.

En términos de tamaño de las superficies regadas y de las pautas de gestión del agua de riego derivadas del medio físico está planteada la clasificación de Karl Butzer (1989). Sus tres tipologías, modificadas y actualizadas por otras iniciativas (Hermosilla, 2010), hacen referencia a las diferentes escalas espaciales: microescala y sistemas menores, mesoescala y sistemas intermedios, y macroescala y grandes sistemas. Los regadíos de microescala son habituales de las áreas montañosas, en espacios limitados en torno a ramblas, barrancos y fuentes, que se basa en riegos estacionales. Los sistemas y los elementos hidráulicos adaptados al medio natural, como las técnicas del abancalamiento tradicional mediterráneo. Entre unos escasos centenares de hectáreas (200-300) y unas miles de hectáreas (2.0003.000), según los espacios analizados y los especialistas constultados, se encuentran sistemas adscritos al escalafón intermedio, los definidos como mesoescala, que corresponden a los riegos de vega (Figura 1). Se trata de sistemas que dependen de azudes y en ocasiones ampliados con pozos. El caudal es continuo, permanente, pero irregular por el régimen fluvial mediterráneo. La gestión suele ser más compleja que la de los microrregadíos del sector montañoso. Los regadíos mayores, identificados como de megaescala, aparecen en los llanos aluviales y litorales de la Comunitat Valenciana y constituyen los sistemas más complejos, por los elementos hidráulicos utilizados para su captación, distribución y uso, merced a un caudal permanente aunque irregular de los principales ejes fluviales. La gestión de esos recursos hídricos se realiza mediante órganos tradicionales caracterizados por su complejidad. 


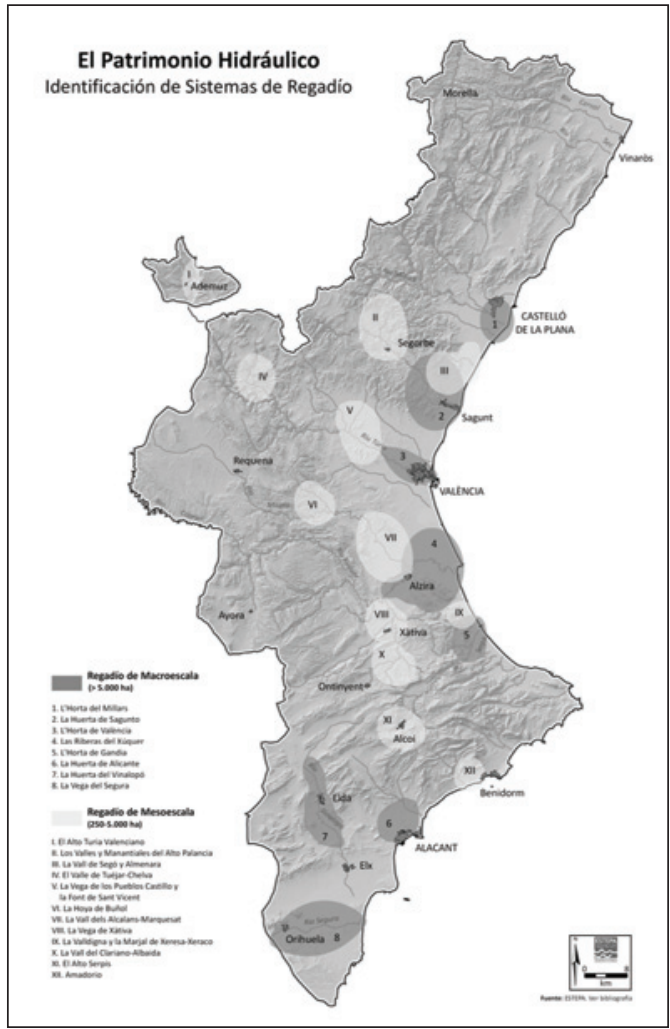

\section{CONSIDERACIONES FINALES EN TORNO A LOS REGADÍOS HISTÓRICOS VALENCIA- NOS. SIMILITUDES Y DIFERENCIAS PRESENTES EN UN ESCENARIO DE PERSPECTIVAS INCIERTAS}

En las últimas décadas se han intensificado los procesos y dinámicas que dan lugar a la depreciación paisajística y patrimonial de los regadíos históricos mediterráneos, y a su desaparición. Por ejemplo, la superficie regada por las ocho acequias madre de la Huerta de València ascendía a unas 15.000 hectáreas en 1950, mientras que en 2010 apenas 8.600 hectáreas. Una reducción del $43 \%$ de media, que en algunas de ellas ha superado el $80 \%$ de la superficie regada (acequias de Rovella, Mestalla y Mislata). En términos generales han actuado y siguen incidiendo varios procesos que repercuten negativamente sobre los escenarios diversos de los regadíos históricos valencianos como la urbanización incesante, las políticas permisivas de cambios de usos del suelo, la sustitución de cultivos tradicionales por otros más comerciales, el éxodo rural y los procesos que desencadenan (envejecimiento, falta de relevo generacional en las explotaciones agrícolas), la sustitución de los sistemas tradicionales de riego por otros modernos (riego localizado, por ejemplo), las reglas del mercado de la tierra que ha favorecido 
la especulación y la generación de ingresos fáciles a corto plazo para los propietarios de la misma, o el desconocimiento por parte de la sociedad del significado cultural y patrimonial de estos espacios y estructuras del agua. Una depreciación que se materializa mediante el abandono de campos abancalados del interior, la proliferación del barbecho social en espacios periurbanos, los cambios de usos del suelo sin control efectivo alguno por parte de la Administración, la arborización de espacios irrigados tradicionales, la fragmentación parcelaria y paisajística, o la sustitución de la acequia y el partidor de riego por el tubo de poliuretano y el ordenador. En definitiva, se ha procedido a nuevas formas de gestión del agua.

La merma patrimonial y paisajística de esos espacios no ha sido ni es homogénea. Son apreciables diferencias en términos de capacidad de producción, en niveles de abandono de las prácticas agrícolas, o en la naturaleza de las producciones cultivadas, entre los modelos de regadíos históricos mediterráneos.

En el litoral-periurbano es frecuente un modelo adaptado a las exigencias de la agricultura comercial, con cultivos reclamados por los mercados nacionales e internacionales, sustentados por infraestructuras hidráulicas que sustituyen a las tradicionales y que tienen por objeto la economía del recurso hídrico; modelo además condicionado, cuando no esquilmado, por la presión ejercida por los cambios de usos del suelo (urbano, industrial, terciario, comunicaciones).

En el interior, definido por las condiciones de ruralidad, el deterioro paisajístico y patrimonial es debido al mantenimiento de estructuras tradicionales, poco competitivas, acompañadas de un sangrante proceso de éxodo rural, envejecimiento de la población y parálisis de las economías locales tradicionales. Se trata de un modelo caracterizado por el abandono del cultivo, por la implantación de una agricultura de subsistencia practicada por mayores, y porque no ha estado ajena a las presiones urbanísticas de las últimas décadas.

Los estudios realizados durante los últimos 15 años por la unidad de investigación ESTEPA (1997-2012), del Departamento de Geografía de la Universitat de València, nos permiten afirmar que entre los sistemas históricos de regadío se constatan diferencias sensibles entre las comarcas valencianas de poniente y de levante, entre la montaña y el llano, entre los espacios de interior y de litoral. Como han señalado varios autores, entre ellos Butzer (1989), a esta dualidad topográfica le corresponde sistemas de riego de desigual tamaño. Como se ha apuntado los sistemas micro y meso son habituales en el interior montañoso, mientras los macro predominan en las amplias llanuras costeras. Esta clasificación obedece a un esfuerzo de síntesis de la complejidad que representan los sistemas de irrigación valencianos, y a un interés didáctico y pedagógico dirigido a la transmisión de las características de los regadíos tradicionales. Sin embargo, esas dimensiones tipo, macrosistemas y microsistemas, no resultan exclusivas del litoral o del interior, ya que otros factores físicos, sociales, tecnológicos o culturales, condicionan igualmente la fisionomía de los espacios regados. Así, la disponibilidad de agua, la organización del poblamiento o el conocimiento y dominio de técnicas de domesticación del agua, han favorecido la presencia secular de microsistemas en numerosas llanuras costeras, asociados al poblamiento islámico y vinculados a la presencia de un acuífero detrítico alimentado por sierras kársticas con abundantes surgencias superficiales (ullals, fuentes, qanats). De la misma manera el desarrollo urbano medieval y moderno, posterior, y la disponibilidad de abundantes recursos hídricos mediante el uso de agua fluvial, permitieron y aceleraron la construcción de las grandes huertas litorales (Sanchis, Hermosilla e Iranzo, 2004). 
Del mismo modo, no se puede diferenciar entre sistemas interiores, en medios montañosos, y litorales, en llanos, cuando procedemos al análisis de los artefactos hidráulicos que conforman los riegos valencianos. Las respuestas tecnológicas a las necesidades de riego en el litoral y en el interior son muy parecidas, basadas en la captación, acumulación y transporte-distribución del agua. Los contrastes existentes tanto en términos de volumen como tipológicos o morfológicos de esos elementos obedecen a los condicionamientos físicos, sociales o históricos, que han intervenido e intervienen en cada comarca valenciana. Por ello, hallamos acueductos y arcos en el territorio valenciano, pero son más numerosos en los sectores más accidentados, en el interior; de la misma manera los azudes se distribuyen por el levante mediterráneo de manera generalizada, no obstante las diferencias en las técnicas y los materiales constructivos son notorios según la comarca tratada se localice en el litoral o en el interior.

Cuadro 1

ELEMENTOS DEL PATRIMONIO HIDRÁULICO DE LA PROVINCIA DE VALENCIA, RELACIONADOS CON EL REGADIOO HISTÓRICO

\begin{tabular}{|l|c|c|}
\hline COMARCAS DE VALENCIA & ELEMENTOS & \% \\
\hline El Camp de Morvedre $\left(^{*}\right)$ & 229 & 4,4 \\
\hline El Camp del Turia & 234 & 4,5 \\
\hline El Rincón de Ademuz & 246 & 4,7 \\
\hline El Valle de Ayora-Cofrentes & 150 & 2,8 \\
\hline Hoya de Buñol-Chiva & 433 & 8,3 \\
\hline La Canal de Navarrés & 280 & 5,4 \\
\hline La Costera & 190 & 3,6 \\
\hline La Plana de Requena-Utiel & 219 & 4,2 \\
\hline La Ribera Alta (*) & 898 & 17,3 \\
\hline La Ribera Baixa $(*)$ & 345 & 6,6 \\
\hline La Safor $(*)$ & 354 & 6,8 \\
\hline La Serranía & 450 & 8,6 \\
\hline La Vall d'Albaida & 700 & 13,4 \\
\hline L'Horta (*) & 462 & 8,9 \\
\hline Provincia de Valencia & $\mathbf{5 . 1 7 3}$ & $\mathbf{1 0 0 \%}$ \\
\hline Comarcas del litoral $(*)$ & $\mathbf{2 . 2 7 6}$ & $\mathbf{4 4 \%}$ \\
\hline Comarcas del interior & $\mathbf{2 . 8 9 7}$ & $\mathbf{5 6 \%}$ \\
\hline
\end{tabular}

Fuente: ESTEPA (1997-2012). Elaboración propia. 


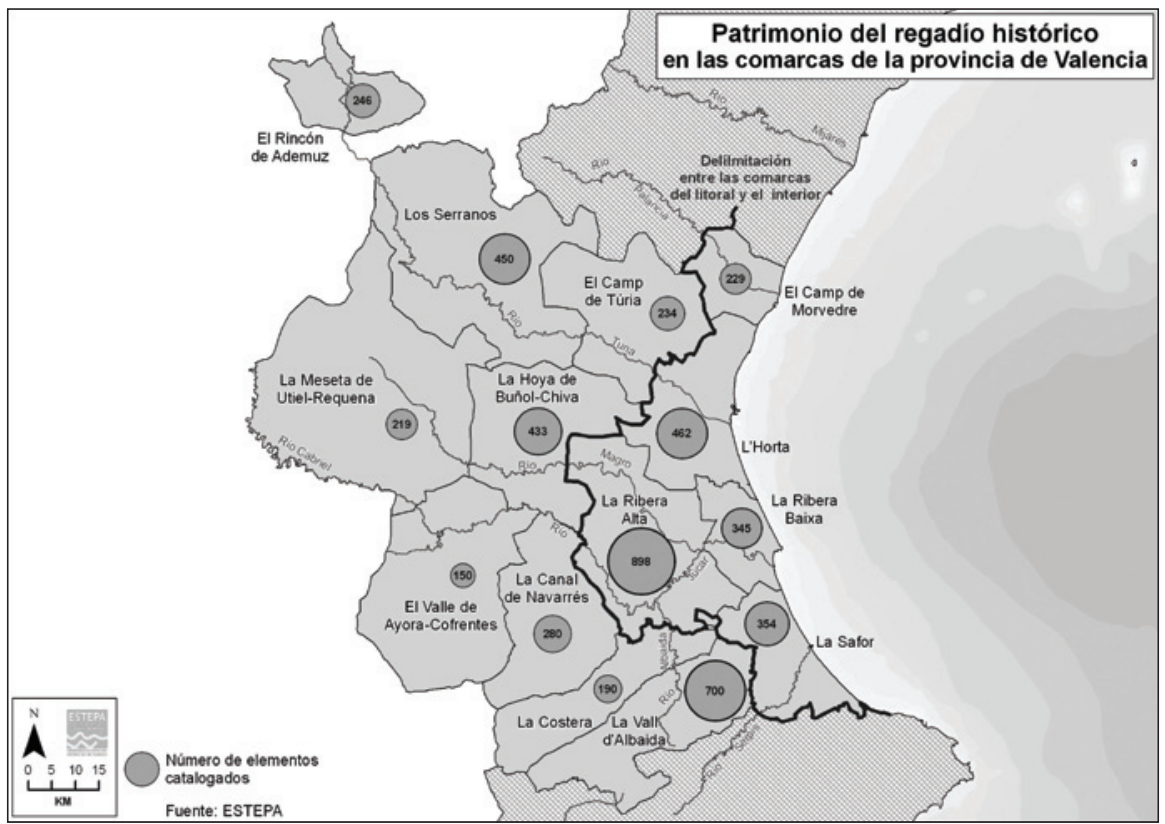

Ahora bien, si consideramos aquellos factores y procesos que afectan a la conservación del patrimonio hidráulico, se constatan algunos rasgos suficientemente significativos como para distinguir diferencias entre la situación de los sistemas de riego del interior y del litoral. En general, son tres los aspectos relacionados con el modelo territorial vigente, ajeno a las dinámicas internas de estos agrosistemas que han garantizado la preservación de estos conjuntos patrimoniales: la presión urbana, los usos e infraestructuras comunes, y la demanda turística y recreativa.

La actual y futura revitalización de los regadíos históricos mediterráneos precisa de la adopción y la adaptación de funciones y actividades que complementen a la tradicional, la producción de cultivos. El futuro de los regadíos históricos pasa por la configuración de espacios multifuncionales, en unos casos extraproductivos, o en otros, profundizando en el cometido tradicional, el productivo.

La actuación sobre estos espacios tradicionales requiere la aplicación de diversas políticas, combinadas, secuenciadas y programadas, que permitan y garanticen el conocimiento real de la situación de los regadíos históricos, mediante las oportunas catalogaciones e inventarios; la adopción de sistemas homologados de valoración y evaluación del patrimonio existente; el diseño de medidas de protección y conservación del patrimonio hidráulico; la divulgación de los valores de dicho patrimonio; y la restitución y la puesta en valor de los mismos. En ese sentido, como ya se ha apuntado en numerosos foros, es recomendable la aplicación de normativas que consideren a los regadíos tradicionales como espacios naturales, así como espacios patrimoniales y paisajísticos necesitados de su ordenación territorial. 
Las diversas administraciones públicas deben tomar conciencia de su significado y adoptar las normas necesarias en los diferentes ámbitos de actuación, como son los ayuntamientos, los gobiernos regionales y nacionales, y la Unión Europea. En la Comunitat Valenciana se han producido en los últimos años acciones puntuales que van dirigidas al reconocimiento de algunos elementos y espacios de dicha consideración patrimonial. En ese sentido sirvan de ejemplos la declaración de BIC de los azudes de L’Horta de València, la redacción del PAT de la Huerta de València (Muñoz, 2010), o actuaciones puntuales en elementos muy significativos, como el acueducto romano de Peña Cortada (Chelva-Calles). No obstante, pese a esas acciones, es constatable el escaso reconocimiento que desde la perspectiva institucional y del plano normativo se realiza a la dimensión real patrimonial de la agricultura tradicional valenciana de regadío. No existen unas figuras de protección bien definidas adaptadas a la realidad y singularidad patrimoniales de los regadíos históricos valencianos. Como acontece en otras partes del territorio español se sigue primando en la consideración de los espacios significados y valorados por sus valores patrimoniales la componente natural y no tanto la cultural. Como señala Silva (2008), los valores naturales priman sobre las cualidades culturales en iniciativas como las Reservas de la Biosfera o los Parques Naturales.

El reconocimiento real del legado de los regadíos históricos valencianos por parte de la sociedad y de sus representantes aún no se ha alcanzado ni aprehendido. Es cierto que hay un reconocimiento del significado histórico y de la valoración paisajística de esos espacios irrigados. Sin embargo se echa en falta una mayor identificación social de las huertas, las vegas, las riberas o los oasis del territorio valenciano; una mayor concienciación por parte de la sociedad y de sus representantes del valor patrimonial y paisajístico de nuestros regadíos. Como se ha apuntado en diversos foros y encuentros (Jornada sobre Regadios Históricos Españoles, en Valencia, mayo de 2010, o Seminario internacional sobre galerías de agua y paisajes asociados, en Valencia, marzo 2011), es muy recomendable, sino imprescindible, la concienciación de la sociedad, el diseño y la aplicación de diversas acciones políticas mediante la participación ciudadana, la dotación presupuestaria de dichas acciones, y la actuación conjunta de equipos multidisciplinares.

\section{BIBLIOGRAFÍA}

AGUILÓ, M. (1999): El paisaje construido. Una aproximación a la idea de lugar. Colegio de Ingenieros de Caminos, Canales y Puertos. Madrid.

ANDERSON, J (2009): Understanding cultural geography. Place and traces. Routledge. New York.

BARCELÓ, M. (1989): «El diseño de espacios irrigados en Al-Andalus: un enunciado de principios generales». Actas del I Coloquio de Historia y Medio Físico, Almería, 14-1516 de diciembre de 1989, Instituto de Estudios Almerienses de la Diputación de Almería, Almería, pp. XV-XLVII.

BUTZER, K.W. et al. (1989): «Orígenes de la distribución intercomunitaria del agua en la Sierra de Espadá». En Los paisajes del agua. Libro jubilar dedicado al profesor Antonio López Gómez. Universitat de València-Universidad de Alicante, pp. 223-228.

CAPELLÀ I MITERNIQUE, H. y LOIS GONZÁLEZ, R. C. (2002): «Geografía cultural: la gran desconocida», Boletín de la Asociación de Geógrafos Españoles, n 34, pp. 11-18.

CLAVAL, P. (1999): La Geografía Cultural. Eudeba, Buenos Aires. 
CLAVAL, P. (2002): «El enfoque cultural y las concepciones geográficas del espacio». Boletín de la Asociación de Geógrafos Españoles, n 34, pp. 21-39

DAUGSTAD, K.; RØNNINGEN, K. y SKAR, B. (2006): «Agriculture as an upholder of cultural heritage? Conceptualizations and value judgements-A Norwegian perspective in international context». Journal of Rural Studies, Vol 22, Issue 1, pp. 67-81.

GIL MESEGUER, E.; MARTÍNEZ MEDINA, R.; GÓMEZ ESPÍN, J.Mª (2011): «Modelos de uso sostenible del agua: las galerías asociadas a presa subálvea». Scripta Nova, Revista Electrónica de Geografía y Ciencias Sociales, Universidad de Barcelona, Vol. $\mathrm{XV}, \mathrm{n}^{\circ} 374$.

GIL MESEGUER, E. (coord.) (2009): Paisaje y patrimonio generados por galerías y minados en la Región de Murcia. Colección Usos del Agua en el Territorio, $\mathrm{n}^{\circ}$ 5, Universidad de Murcia, $175 \mathrm{pp}$.

GIL OLCINA, A. Y MORALES, A. (1992): Hitos históricos de los regadíos españoles. Ministerio de Agricultura, Pesca y Alimentación, Madrid. 415 pp.

HAGGET, P. (1989): Geografía: una síntesis moderna, Barcelona Ediciones Omega. 686 pp.

HERMOSILLA, J. (Dir.) (2010): Los Regadios Históricos Españoles: paisajes culturales, paisajes sostenibles. Colección Gestión tradicional del agua, patrimonio cultural y sostenibilidad, $\mathrm{n}^{\circ}$ 3. Madrid, Ed. Ministerio de Medio Ambiente y Medio Rural y Marino. 600 pp.

HERMOSILLA, J. y ESTRELA, T. (Dirs.) (2012): El patrimonio hidráulico histórico en el Ámbito Territorial de la Confederación Hidrográfica del Júcar. Ministerio de Agricultura, Pesca y Alimentación. Universitat de València.

HERMOSILLA, J. (Dir.) (2012): Las galerías de agua en la cuenca hidrográfica del Júcar. Un patrimonio hidráulico en el Mediterráneo español. Ministerio de Agricultura, Pesca y Alimentación. Universitat de València.

IRANZO, E. (2009): El paisaje como patrimonio rural. Propuesta de una sistemática integrada para el análisis de los paisajes valencianos. Tesis doctoral, PUV, $753 \mathrm{pp}$.

LÓPEZ, A. (1974): «El origen de los riegos valencianos I. Los canales romanos». Cuadernos de Geografía, n 15, pp. 1-24.LÓPEZ, A. (1975): «El origen de los riegos valencianos II. La división del agua». Cuadernos de Geografía, No17, pp. 1-38.

LÓPEZ, A. (1987): Els embassaments valencians antics. Generalitat Valenciana, Conselleria d'Obres Públiques, València. 72 pp.

LÓPEZ, A. (1989): Estudios sobre regadíos valencianos. Universitat de València, Servei de Publicacions. $177 \mathrm{pp}$.

MARCO, J.B., MATEU, J. y ROMERO, J. (1994): Regadios Históricos Valencianos: propuestas de rehabilitación. Conselleria d'Agricultura i Pesca, Servei d'Estudis Agraris i Comunitaris, Generalitat Valenciana. 158 pp.

MARCO, J.B. Y SANCHÍS, C. (2003): «Una aproximación a la evolución de los regadíos valencianos. Infraestructura, hidrología e hidráulica». En El patrimonio histórico de la Ingeniería Civil en la Comunidad Valenciana, Colegio de Ingenieros de Caminos, Canales y puertos de la Comunidad Valenciana, Valencia. $254 \mathrm{pp}$.

MARTINEZ, J. y ESTEVE, M.A. (2001): «Evolución de los regadíos tradicionales del sudeste ibérico: aplicación de un modelo de simulación dinámica». Congreso Ibérico de gestión y planificación de Aguas. Sevilla. 
MATA, R. y FERNÁNDEZ, S. (2010): «Paisajes y patrimonios culturales del agua. La salvaguarda del valor patrimonial de los regadíos tradicionales» en Scripta Nova. Revista electrónica de Geografía y Ciencias Sociales, Vol. XIV, nº 337. Universitat de Barcelona.

MIRALBÉS, R. e HIGUERAS, A. (1993): «Reflexiones sobre el espacio geográfico», Geographicalia $n^{\circ} 30$, pp. 283-294.

MITCHELL, D. (1996) «California: The Beautiful and the Damned» en OAKES, T y PRICE, P. (2008): The Cultural Geography Reader. Routledge. New York.

MORALES, A. y GIL, A. (1992): Hitos históricos de los regadios españoles. Ministerio de Agricultura, Pesca y Alimentación. Madrid.

MORALES, A. (1989): «Abandono y desorganización de los sistemas de riegos de turbias. Su incidencia en la escorrentía», en Los paisajes del agua. Libro jubilar dedicado al profesor Antonio López Gómez. Valencia, Universidad de Alicante y Universidad de Valencia, pp.199-204

MUÑOZ, A. (2010): Plan de Acción Territorial de protección de la Huerta de Valencia. Generalitat Valenciana.

PIQUERAS, J. (1993): «Les obres de reg valencianes: l'origen i l'estat actual». Lauro, n 7 , pp. 31-40.

RIOJA, C. (1999): «La catalogación del patrimonio etnográfico como medio de protección», Patrimonio Etnológico: nuevas perspectivas de estudio. Instituto Andaluz del Patrimonio Histórico. Sevilla, pp. 84-93.

SANCHIS, C., HERMOSILLA, J. e IRANZO, E. (2004): «Entorn al patrimoni hidràulic del regadiu històric valencià». Pp. 223-236. En Patrimoni rural valenciano, SaitabI, n 54 , pp. 223-236.

SANCHIS, C. (1999): «Patrimoni cultural a les hortes valencianes». Hortes valencianes: la fi d'un mite?. Mètode, no 22, Universitat de València, pp. 19-21.

SILVA, R. (2008): «Hacia una valoración patrimonial de la agricultura» en Scripta Nova. Revista electrónica de Geografía y Ciencias Sociales, Vol. XII, nº 275. Universitat de Barcelona.

SILVA, R. (2009): «Agricultura, paisajes y patrimonio territorial. Los paisajes de la agricultura vistos como patrimonio». Boletín de la Asociación de Geógrafos Españoles, n 49 , pp. 309-334

(*) El presente artículo se ha servido de la experiencia acumulada durante las investigaciones de la unidad ESTEPA (Departament de Geografia, Universitat de València), mediante la elaboración de proyectos sobre riegos tradicionales y el patrimonio hidráulico desarrollados por el territorio valenciano a lo largo de los últimos quince años. Bajo la dirección del profesor Jorge Hermosilla, parte de estas investigaciones han sido publicadas en la Colección Regadíos Históricos Valencianos, de la Dirección General de Patrimonio Cultural Valenciano, la Universitat de València y la Confederación Hidrográfica del Júcar: El Patrimonio del agua en el Valle de Ayora-Cofrentes (1999); Los sistemas de regadío en La Costera. Paisaje y Patrimonio (2003); La Arquitectura del agua en el Riu Magre. Alcalans-Marquesat (2004); El regadío histórico en la comarca de Requena-Utiel. Geografía y Patrimonio (2005); Los Riegos de la Safor y la Valldigna. Agua, Territorio y Tradición (2005); Los Paisajes de Regadío en el Alto Palancia. Sistemas y elementos hidráulicos (2006); Las Riberas del Xúquer: Paisajes y patrimonio Valenciano (2006); Los regadíos tradicionales del Vinalopó. Alto y Medio (2007); El patrimonio hidráulico del Bajo Túria: L'Horta de València (2007); Las vegas tradicionales del Alto Turia: sistemas y paisajes de regadío (2008); Los regadíos históricos del Turia Medio: La Serranía y el Camp de Turia (2009); Los regadíos históricos del Baix Millars-La Plana (2009); Los regadíos tradicionales y el patrimonio hidráulico del Alto Mijares (2010); y Los riegos tradicionales de La Marina Alta: las cuencas hidrográficas del Gorgos y Girona (2012); coeditados por el Servicio de Publicaciones de la Universitat de València y la Dirección General de Patrimonio Cultural Valenciano. 